\section{High-Tech Garage Showcases Strategies for Reducing Energy}

Even from a distance, the parking structure on the U.S. Department of Energy's National Renewable Energy Laboratory (NREL) campus doesn't look like an ordinary parking garage. And it doesn't act like one either. NREL's parking structure, which opened in 2012, proves that large garages can be designed and built sustainably —at no additional cost.

In addition to meeting staff needs with up to 1,800 parking spaces, this 578,320 square-foot, five-level structure is a showcase for energy efficiency and renewable energy technologies.

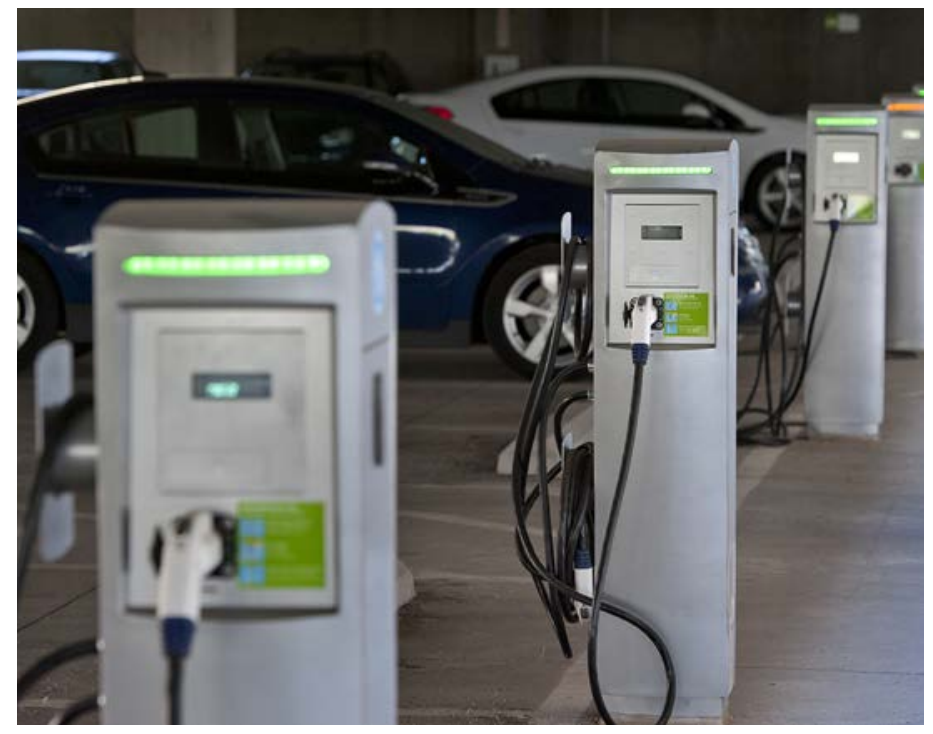

The parking garage includes 36 electric vehicle charging stations that are available for employee use.

Photo by Dennis Schroeder, NREL 21661

Parking Spaces:

Approximately 1,800

- 90 preferred spaces for carpooling and vanpooling

- 90 preferred spaces for low-emitting vehicles

- 36 electric vehicle charging stations

Energy Use:

Less than 160 kBTUs per parking space per year (projected)

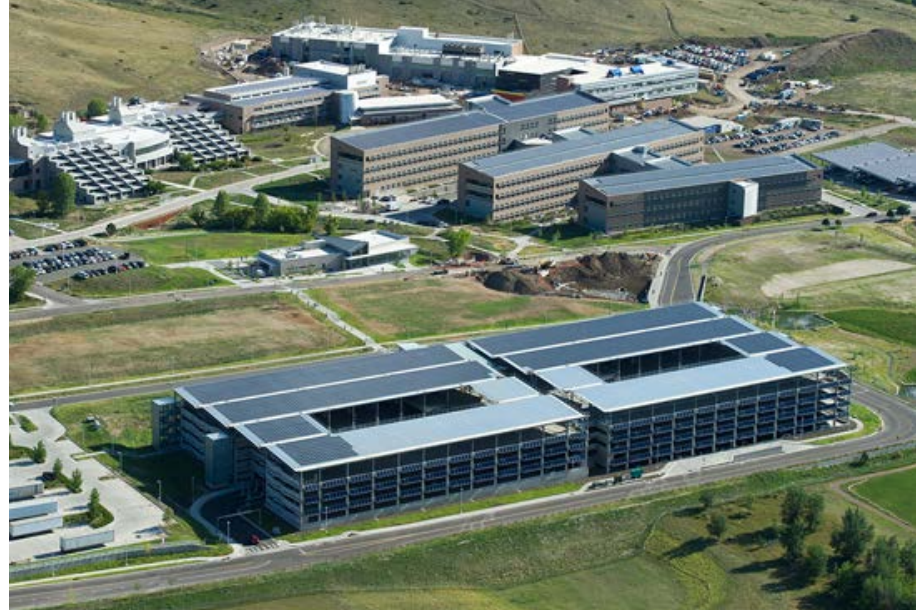

Renewable energy power is produced from photovoltaic panels on the garage rooftop and on the south façade. Photo by Dennis Schroeder, NREL 21806

\section{Energy Efficiency}

- The garage reduces its need for electric lighting through a number of features:

- Daylighting, enhanced by large light wells and an open central atrium, reduces the need for electric lighting by $75 \%$ to $100 \%$ during daytime hours;

- Occupancy and daylighting sensors that automatically turn lights on when needed; and

- Highly energy efficient LED lighting.

- Digital signs indicate available parking spaces and help reduce driving and emissions.

- The garage only has two elevators, significantly reducing energy usage and encouraging employees to take the stairs.

- Sides that open to the elements allow for natural ventilation, eliminating the need for a mechanical system.

\section{Energy Performance:}

90\% more efficient than ASHRAE 90.12007 standards

\section{Solar Power:}

1.153 MW on rooftop and south façade

Cost:

$\$ 14,172$ per parking space*

*Cost for typical parking space: $\$ 15,500$ to $\$ 24,500$ 


\section{Renewable Energy}

- The parking garage has a 1.153 MW rooftop and south façade photovoltaic array. The environmental attributes - known as RECs (Renewable Energy Credits) - are sold to Xcel Energy to meet Colorado's Renewable Portfolio Standard.

- 36 electric vehicle charging stations are available for employee use.

\section{Water Conservation}

- Storm water is passed through a drainage system from the rooftop and surrounding areas to an adjacent detention pond.

- Native and drought-resistant vegetation surround the garage and help it blend into the natural surroundings.

\section{Building Materials}

In addition to functional and aesthetic value, building materials were selected for sustainability and durability.
- The façade, clad with recyclable perforated aluminum, provides weather protection while maximizing daylighting and ventilation.

- About $35 \%$ of building materials contain recycled content.

- Building glazing is lined with a ceramic striped pattern to reduce bird strike fatalities.

\section{Minimizing Waste}

About three-fourths of all building construction waste was recycled and diverted from the waste stream.

\section{More Garage Features}

Besides convenient, covered parking, other garage features include:

- A book donation bin and recycling drop-off center,

- A protected shuttle stop for employees to access campus facilities, and

- Bike parking and small gear lockers.

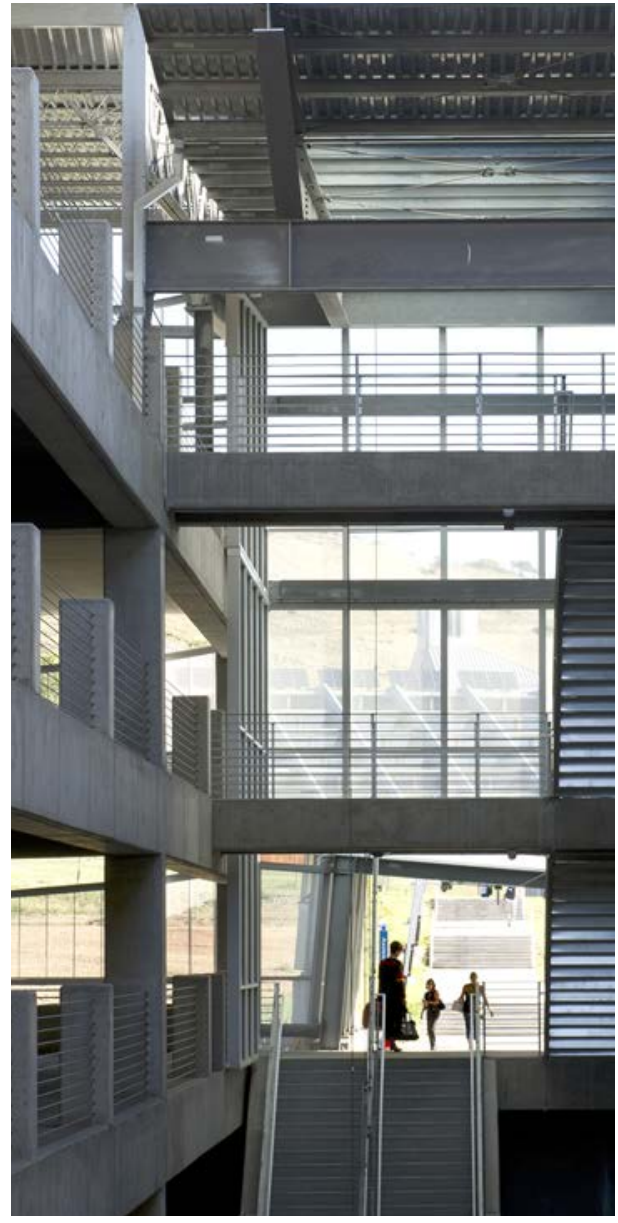

A large, daylit central atrium and staircase improves safety and encourages activity for employees, while reducing the energy used by elevators and lighting.

Photo by Dennis Schroeder, NREL 21659

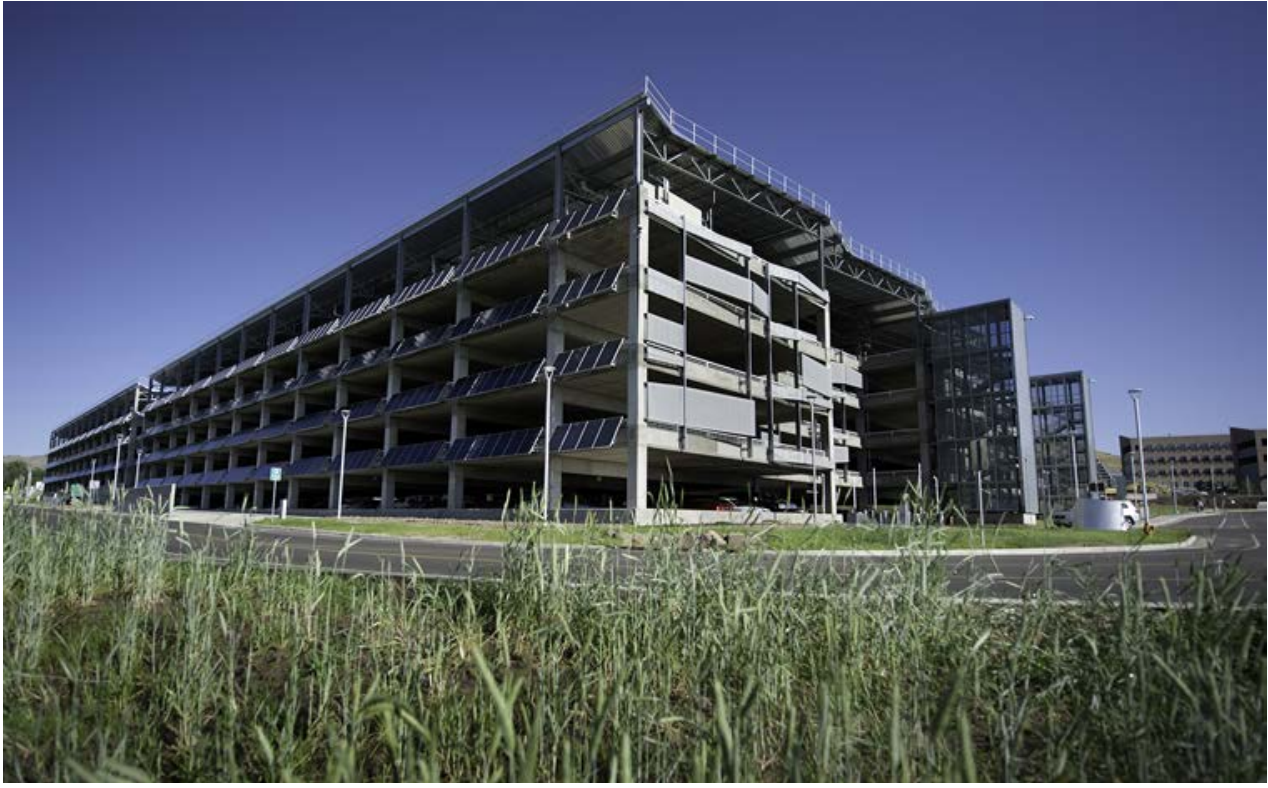

The garage on NREL's South Table Mountain campus is a central location for employees to begin and end their day, accessing the campus via foot, bike, or shuttle buses.

Photo by Dennis Schroeder, NREL 21633

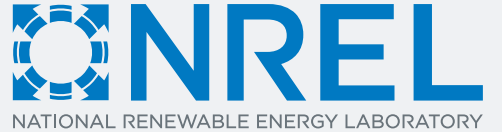

National Renewable Energy Laboratory 15013 Denver West Parkway Golden, C0 80401

303-275-3000 • www.nrel.gov

NREL is a national laboratory of the U.S. Department of Energy, Office of Energy Efficiency and Renewable Energy, operated by the Alliance for Sustainable Energy, LLC.

NREL/FS-3500-58137・ March 2013

Printed with a renewable-source ink on paper containing at least $50 \%$ wastepaper, including $10 \%$ post consumer waste. 